\title{
Chronic Obstructive Pulmonary Disease and Employment Among Massachusetts Adults
}

\author{
Kathleen Fitzsimmons, $\mathrm{PhD}^{1}$; Elise Pechter, $\mathrm{MPH}^{1}$; Emily Sparer-Fine, $\mathrm{ScD}^{1}$
}

Accessible Version: www.cdc.gov/pcd/issues/2020/20_0116.htm

Suggested citation for this article: Fitzsimmons K, Pechter E, Sparer-Fine E. Chronic Obstructive Pulmonary Disease and Employment Among Massachusetts Adults. Prev Chronic Dis 2020;17:200116. DOI: https://doi.org/10.5888/pcd17.200116.

\section{PEER REVIEWED}

\section{Summary}

What is already known about this topic?

Chronic obstructive pulmonary disease (COPD) is an important cause of disability and death in the United States. Occupational exposure accounts for $10 \%$ to $15 \%$ of the total burden, but employment may also enhance health and well-being for people with COPD.

What is added by this report?

Massachusetts workers with COPD were more likely than those without COPD to report indicators of poor physical and mental health. Distribution by occupation differed between the two groups.

What are the implications for public health practice?

Findings suggest that workplace interventions that support and retain workers with COPD may be needed.

\section{Abstract}

Occupational exposure may cause or exacerbate chronic obstructive pulmonary disease (COPD), but employment may also enhance health and well-being for people with the disorder. We used self-reported data from the 2011-2017 Massachusetts Behavioral Risk Factor Surveillance System to examine COPD and employment among adults aged 40 to 70 . Thirty-nine percent of adults with COPD were employed. Workers with COPD were more likely than those without COPD to report indicators of poor physical and mental health, and distribution by occupation differed between the 2 groups. Findings suggest workplace interventions may be needed to prevent respiratory exposures and enhance support for employees with COPD.

\section{Objective}

Chronic obstructive pulmonary disease (COPD), a chronic, progressive lung disease, affects an estimated 15.5 million US adults (1). It is a leading cause of death and imposes a high human and financial toll in terms of hospital visits and related charges $(2,3)$. Work in certain industries and occupations is associated with COPD, and workplace exposure accounts for $10 \%$ to $15 \%$ of the disease burden (4-6). However, employment may enhance health and well-being for people with COPD (7). Our objective was to examine COPD and employment among Massachusetts adults, including occupation, and compare workers with and without COPD to inform interventions that support health and the ability to work.

\section{Methods}

The Behavioral Risk Factor Surveillance System (BRFSS) is an annual state-based, random-digit-dialed landline and cellular telephone survey of noninstitutionalized adults aged 18 or older that collects prevalence data on health conditions, health-related behaviors, and indicators of health care access (8). For our crosssectional study, we used self-reported data from the 2011-2017 Massachusetts BRFSS. Annual survey response rates from the 2011-2017 survey ranged from $32.5 \%$ to $42.0 \%$. The data were weighted to represent the adult population of Massachusetts. Our analysis was restricted to adults aged 40 to 70 years who answered both the employment and COPD questions $(\mathrm{N}=56,052)$. COPD was defined as an affirmative response to the question, "Has a doctor, nurse, or other health professional ever told you that you had chronic obstructive pulmonary disease or COPD, emphysema, or chronic bronchitis?" We defined workers as respondents who reported being employed for wages, self-employed, or out of work for less than 1 year. Open-ended questions on occupation and industry were asked of workers each year in the Massachusetts BRFSS survey. Based on responses, 2002 Census occupation codes (COC) were assigned by the National Institute for Occupational Safety and Health by using computer-assisted methods and were included in the annual data sets. Individual codes were grouped into the following standard occupation categories for analysis: Management, Business and Financial Operations (COC 
0010-0950); Professional and Related (1000-3540); Service (3600-4650); Sales and Related (4700-4960); Office and Administrative Support (5000-5930); Transportation and Material Moving (9000-9750); and Other. Weighted percentages and 95\% CIs were estimated by using SAS version 9.4 (SAS Institute). We compared weighted distributions by using $\chi^{2}$ tests of independence.

\section{Results}

Prevalence of COPD was $6.7 \%$ (95\% CI, 6.4\%-7.0\%) among Massachusetts adults aged 40 to 70 . Compared with adults without COPD, higher percentages of those with COPD were unable to work (33.3\% vs $7.4 \%$ ), retired ( $18.2 \%$ vs $12.2 \%)$, or out of work for 1 year or more $(6.2 \%$ vs $3.8 \%)$ (Table 1$)$. Among adults with COPD, 39.4\% had worked in the past year, compared with $72.1 \%$ of those without COPD.

An estimated 3.8\% (95\% CI, 3.5\%-4.1\%) of workers had COPD. Workers with COPD were more likely than those without COPD to be older, female, non-Hispanic White, and have completed high school or a lower level of education (Table 1). They were more likely to report current asthma ( $38.0 \%$ vs $8.1 \%$ ), describe their overall health as fair or poor $(27.9 \% \mathrm{vs} 7.0 \%)$, and report poor mental health for $\geq 15$ days in the previous month (19.9\% vs. $6.8 \%$ ). Only $48.4 \%$ reported having an influenza vaccination in the past year. Workers with COPD were more likely to be current or former smokers; $24.0 \%$ had never smoked. Among nonsmokers, $15.8 \%$ of those with COPD reported exposure to secondhand smoke at work in the past week, compared with $8.8 \%$ of those without COPD.

The overall distribution by occupation differed between the 2 groups $(P<.001)$ (Table 2$)$. Workers with COPD were more likely to work in Service (19.3\% vs $11.9 \%$ ) and Office and Administrative Support (16.9\% vs 10.5\%) occupations and less likely in Management, Business and Financial Operations (12.5\% vs $17.0 \%)$ and Professional and Related (22.0\% vs $35.4 \%)$ occupations. The percentage in Service occupations tended to decrease with increasing age, and the percentage in Office and Administrative Support and Professional and Related occupations tended to increase, although estimates were imprecise. The distribution of workers without COPD by occupation varied less across age groups than those with COPD.

\section{Discussion}

Our study quantified the relationship between COPD and employment, raising questions about how occupation-related factors may improve health and prolong careers of workers with COPD. Nearly $40 \%$ of workers in our study with COPD continued to work, despite facing challenges. Continuing employment may confer health advantages, beyond income, including health insurance-related benefits (eg, influenza vaccinations, smoking cessation programs) and psychosocial support (7). A healthy workplace, devoid of secondhand smoke, dusts, fumes, gases, and vapors may prevent COPD onset and exacerbations $(6,9)$.

Poor physical or mental health among workers with COPD, further affected by comorbidities like asthma, may affect their capacity to work or prompt a job change (10). Continued employment may be dependent on job type, demands, and flexibility of the employer (11). Findings by occupation suggest differences in the distribution by age among workers with COPD that are not seen in those without. This may indicate a shift to jobs that are less hazardous or labor intensive or that enable disease management (eg, flexible work schedule). It may also indicate that workers in certain high-risk occupations leave the workforce at younger ages as exposures become less tolerable or as their disease progresses (11).

Our study had limitations. First, the COPD measure was based on self-report and not medically validated. However, previous research found self-report to be consistent with objective evidence of COPD (12). Next, the proportion of workers with COPD may have been underestimated because of underdiagnosis, especially in nonsmokers. Next, the Massachusetts BRFSS is limited to noninstitutionalized adults who speak English, Spanish, or Portuguese. Lastly, we cannot infer causality about COPD and employment because the BRFSS is cross-sectional.

In conclusion, our findings suggest that interventions that support and retain workers with COPD may be needed. Further research into workplace conditions and organizational factors that best promote respiratory health would inform efforts.

\section{Acknowledgments}

We acknowledge the following people for their helpful review: Maria McKenna, Office of Data Management and Outcomes Assessment, Massachusetts Department of Public Health, and Lindsay Kephart, Tobacco Cessation and Prevention Program, Bureau of Community Health and Prevention, Massachusetts Department of Public Health. This work was supported by Cooperative Agreement number 5U60OH008490 from the Centers for Disease Control and Prevention (CDC). Contents are solely the responsibility of the authors and do not necessarily represent the official views of the CDC. No copyrighted materials, surveys, instruments, or tools were used in this study.

The opinions expressed by authors contributing to this journal do not necessarily reflect the opinions of the U.S. Department of Health and Human Services, the Public Health Service, the Centers for Disease Control and Prevention, or the authors' affiliated institutions. 


\section{Author Information}

Corresponding Author: Kathleen Fitzsimmons; Massachusetts Department of Public Health, 250 Washington St, 4th Floor, Boston, MA 02108. Telephone: 617-624-5624. Email: kathleen.fitzsimmons@mass.gov.

Author Affiliations: ${ }^{1}$ Occupational Health Surveillance Program, Bureau of Community Health and Prevention, Massachusetts Department of Public Health, Boston, Massachusetts.

\section{References}

1. Croft JB, Wheaton AG, Liu Y, Xu F, Lu H, Matthews KA, et al. Urban-rural county and state differences in chronic obstructive pulmonary disease - United States, 2015. MMWR Morb Mortal Wkly Rep 2018;67(7):205-11.

2. National Center for Health Statistics. Health, United States, 2018 - Data Finder. Hyattsville, Maryland. Published 2019. https://www.cdc.gov/nchs/hus/contents2018.htm\#Table 006. Accessed March 6, 2020.

3. Hasegawa K, Tsugawa Y, Tsai CL, Brown DF, Camargo CA Jr. Frequent utilization of the emergency department for acute exacerbation of chronic obstructive pulmonary disease. Respir Res 2014;15(1):40-52.

4. Kurth L, Doney B, Halldin C, Hale J, Frenk SM. Airflow obstruction among ever-employed U.S. adults aged 18-79 years by industry and occupation: NHANES 2007-2008 to 2011-2012. Am J Ind Med 2019;62(1):30-42.

5. Syamlal G, Doney B, Mazurek JM. Chronic obstructive pulmonary disease prevalence among adults who have never smoked, by industry and occupation - United States, 2013-2017. MMWR Morb Mortal Wkly Rep 2019; 68(13):303-7.

6. Fishwick D, Sen D, Barber C, Bradshaw L, Robinson E, Sumner J; COPD Standard Collaboration Group. Occupational chronic obstructive pulmonary disease: a standard of care. Occup Med (Lond) 2015;65(4):270-82.

7. Waddell G, Burton AK. Is work good for your health and wellbeing? https://cardinal-management.co.uk/wp-content/uploads/ 2016/04/Burton-Waddell-is-work-good-for-you.pdf. Published 2006. Accessed March 6, 2020.

8. Centers for Disease Control and Prevention. The BRFSS data user guide. Published 2013. https://www.cdc.gov/brfss/data documentation/pdf/UserguideJune2013.pdf. Accessed May 10, 2020.
9. De Matteis S, Jarvis D, Darnton A, Hutchings S, Sadhra S, Fishwick D, et al. The occupations at increased risk of COPD: analysis of lifetime job-histories in the population-based UK Biobank Cohort. Eur Respir J 2019;54(1):1900186.

10. Kumbhare S, Pleasants R, Ohar JA, Strange C. Characteristics and prevalence of asthma/chronic obstructive pulmonary disease overlap in the United States. Ann Am Thorac Soc 2016;13(6):803-10.

11. Fletcher MJ, Upton J, Taylor-Fishwick J, Buist SA, Jenkins C, Hutton J, et al. COPD uncovered: an international survey on the impact of chronic obstructive pulmonary disease [COPD] on a working age population. BMC Public Health 2011; 11(1):612-24.

12. Radeos MS, Cydulka RK, Rowe BH, Barr RG, Clark S, Camargo CA Jr. Validation of self-reported chronic obstructive pulmonary disease among patients in the ED. Am J Emerg Med 2009;27(2):191-6.

The opinions expressed by authors contributing to this journal do not necessarily reflect the opinions of the U.S. Department of Health and Human Services, the Public Health Service, the Centers for Disease Control and Prevention, or the authors' affiliated institutions. 


\section{Tables}

Table 1. Characteristics of Massachusetts Adults and Workers ${ }^{\mathrm{a}}$ Aged 40 to 70 , by COPD Status ${ }^{\mathrm{b}}$, Massachusetts BRFSS, 2011-2017

\begin{tabular}{|c|c|c|c|c|c|}
\hline \multirow[b]{2}{*}{ Characteristic $^{b}$} & \multicolumn{2}{|c|}{ With COPD } & \multicolumn{2}{|c|}{ Without COPD } & \multirow[b]{2}{*}{$P$ Value ${ }^{e}$} \\
\hline & No. Responding ${ }^{c}$ & $\%(95 \% \mathrm{Cl})^{\mathrm{d}}$ & No. Responding ${ }^{c}$ & $\%(95 \% \mathrm{Cl})^{d}$ & \\
\hline \multicolumn{6}{|c|}{ All Adults, $\mathrm{N}=56,052$} \\
\hline Employment status & \multirow[t]{6}{*}{4,623} & NA & \multirow[t]{6}{*}{51,429} & NA & \multirow[t]{6}{*}{$<.001$} \\
\hline Unable to work & & $33.3(31.0-35.6)$ & & $7.4(7.0-7.7)$ & \\
\hline Retired & & $18.2(16.5-19.9)$ & & $12.2(11.8-12.6)$ & \\
\hline Out of work for $\geq 1$ year & & $6.2(4.8-7.5)$ & & $3.8(3.6-4.1)$ & \\
\hline Other (Student, homemaker) & & $2.9(2.1-3.8)$ & & $4.6(4.3-4.9)$ & \\
\hline Employed, past year ${ }^{a}$ & & $39.4(37.0-41.8)$ & & $72.1(71.5-72.6)$ & \\
\hline \multicolumn{6}{|c|}{ Workers, $n=35,906$} \\
\hline Age, $y$ & \multirow[t]{4}{*}{1,514} & NA & \multirow[t]{4}{*}{34,392} & NA & \multirow[t]{4}{*}{$<.001$} \\
\hline $40-50$ & & $28.5(24.8-32.2)$ & & $45.2(44.5-46.0)$ & \\
\hline $51-60$ & & $44.9(40.9-48.9)$ & & $38.7(37.9-39.4)$ & \\
\hline $61-70$ & & $26.6(23.4-29.9)$ & & $16.1(15.6-16.6)$ & \\
\hline Female & 1,514 & $58.0(54.0-62.0)$ & 34,392 & $48.6(47.9-49.4)$ & $<.001$ \\
\hline Race/ethnicity & \multirow[t]{5}{*}{1,491} & NA & \multirow[t]{5}{*}{33,905} & NA & \multirow[t]{5}{*}{.07} \\
\hline White, non-Hispanic & & $87.2(84.0-90.4)$ & & $82.6(81.9-83.3)$ & \\
\hline Hispanic & & $4.1(2.4-5.7)$ & & $6.5(6.0-6.9)$ & \\
\hline Black, non-Hispanic & & $3.5(1.6-5.5)$ & & $5.4(5.0-5.7)$ & \\
\hline Other, non-Hispanic & & $5.2(2.9-7.5)$ & & $5.6(5.2-6.1)$ & \\
\hline Education & \multirow[t]{3}{*}{1,509} & $\mathrm{NA}$ & \multirow[t]{3}{*}{34,310} & NA & \multirow[t]{3}{*}{$<.001$} \\
\hline$\leq$ High school graduate & & $48.0(44.0-52.1)$ & & $29.3(28.5-30.1)$ & \\
\hline >High school graduate & & $52.0(47.9-56.0)$ & & $70.7(69.9-71.5)$ & \\
\hline
\end{tabular}

Abbreviations: BRFSS, Behavioral Risk Factor Surveillance System; COPD, chronic obstructive pulmonary disease; NA, not applicable.

${ }^{a}$ Employed for wages, self-employed, or out of work for less than 1 year.

b "Yes" (with COPD) or "no" (without COPD) response to the question: "Has a doctor, nurse, or other health professional ever told you that you had chronic obstructive pulmonary disease or COPD, emphysema, or chronic bronchitis?"

${ }^{c}$ Unweighted number of respondents who answered the corresponding question(s). The numbers might not total the full study group because not all respondents answered each question.

${ }^{d}$ Weighted percentage. Percentages may not add to $100 \%$ because of rounding.

${ }^{\mathrm{e}} P$ value from $x^{2}$ test of independence comparing weighted distributions between those with and without COPD.

$f$ "Yes" response to the question: "Have you ever been told by a doctor or other health professional that you have asthma?"

g "Yes" responses to the questions: "Have you ever been told by a doctor or other health professional that you have asthma?" and "Do you still have asthma?"

${ }^{\mathrm{h}}$ Responded "fair" or "poor" when asked to describe his/her overall health as excellent, very good, good, fair, or poor.

${ }^{i}$ Responded 15 days or more when asked the number days in the past month that his/her physical health, which includes physical illness and injury, had not been good.

${ }^{j}$ Responded 15 days or more when asked the number of days in the past month that his/her mental health, which includes stress, depression, and problems with emotions, had not been good.

${ }^{k}$ Current = smoked at least 100 cigarettes in his/her lifetime and currently smokes either some days or every day; former = smoked at least 100 cigarettes in his/ her lifetime but no longer smokes.

' Responded 1 or more hours when asked the number of hours exposed to other people's tobacco smoke when at work in the past 7 days.

The opinions expressed by authors contributing to this journal do not necessarily reflect the opinions of the U.S. Department of Health and Human Services, the Public Health Service, the Centers for Disease Control and Prevention, or the authors' affiliated institutions. 
(continued)

Table 1. Characteristics of Massachusetts Adults and Workers ${ }^{a}$ Aged 40 to 70 , by COPD Status ${ }^{b}$, Massachusetts BRFSS, 2011-2017

\begin{tabular}{|c|c|c|c|c|c|}
\hline \multirow[b]{2}{*}{ Characteristic $^{\mathrm{b}}$} & \multicolumn{2}{|c|}{ With COPD } & \multicolumn{2}{|c|}{ Without COPD } & \multirow[b]{2}{*}{$P$ Value } \\
\hline & No. Responding ${ }^{c}$ & $\%(95 \% \mathrm{Cl})^{\mathrm{d}}$ & No. Responding ${ }^{c}$ & $\%(95 \% \mathrm{Cl})^{\mathrm{d}}$ & \\
\hline Ever diagnosed with asthma ${ }^{f}$ & 1,503 & $45.2(41.2-49.1)$ & 34,326 & $11.5(11.0-12.0)$ & $<.001$ \\
\hline Current asthma ${ }^{g}$ & 1,491 & $38.0(34.1-41.9)$ & 34,233 & $8.1(7.6-8.5)$ & $<.001$ \\
\hline \multicolumn{6}{|l|}{ Physical health } \\
\hline Fair or poor ${ }^{\mathrm{h}}$ & 1,513 & $27.9(24.5-31.4)$ & 34,338 & $7.0(6.6-7.4)$ & $<.001$ \\
\hline Poor, $\geq 15$ days past month ${ }^{i}$ & 1,486 & $20.6(17.5-23.8)$ & 33,992 & $5.5(5.2-5.9)$ & $<.001$ \\
\hline Poor mental health, $\geq 15$ days past month ${ }^{j}$ & 1,483 & $19.9(16.7-23.2)$ & 33,913 & $6.8(6.4-7.2)$ & $<.001$ \\
\hline Influenza vaccination, past year & 1,412 & $48.4(44.2-52.5)$ & 31,911 & $43.9(43.1-44.7)$ & .04 \\
\hline Smoking status ${ }^{\mathrm{k}}$ & \multirow[t]{4}{*}{1,476} & NA & \multirow[t]{4}{*}{33,244} & NA & \multirow[t]{4}{*}{$<.001$} \\
\hline Current & & $39.3(35.3-43.3)$ & & $12.4(11.9-13.0)$ & \\
\hline Former & & $36.7(32.9-40.4)$ & & $30.3(29.5-31.0)$ & \\
\hline Never & & $24.0(20.6-27.5)$ & & $57.3(56.5-58.1)$ & \\
\hline $\begin{array}{l}\text { Secondhand smoke exposure at work, past } \\
\text { week }\end{array}$ & 971 & $18.1(13.9-22.4)$ & 22,942 & $10.0(9.3-10.7)$ & $<.001$ \\
\hline Among nonsmokers & 606 & $15.8(10.9-20.6)$ & 20,193 & $8.8(8.1-9.4)$ & $<.001$ \\
\hline
\end{tabular}

Abbreviations: BRFSS, Behavioral Risk Factor Surveillance System; COPD, chronic obstructive pulmonary disease; NA, not applicable.

${ }^{a}$ Employed for wages, self-employed, or out of work for less than 1 year.

b "Yes" (with COPD) or "no" (without COPD) response to the question: "Has a doctor, nurse, or other health professional ever told you that you had chronic obstructive pulmonary disease or COPD, emphysema, or chronic bronchitis?"

${ }^{\mathrm{c}}$ Unweighted number of respondents who answered the corresponding question(s). The numbers might not total the full study group because not all respondents answered each question.

${ }^{d}$ Weighted percentage. Percentages may not add to $100 \%$ because of rounding.

e $P$ value from $x^{2}$ test of independence comparing weighted distributions between those with and without COPD.

f "Yes" response to the question: "Have you ever been told by a doctor or other health professional that you have asthma?"

g "Yes" responses to the questions: "Have you ever been told by a doctor or other health professional that you have asthma?" and "Do you still have asthma?"

${ }^{\mathrm{h}}$ Responded "fair" or "poor" when asked to describe his/her overall health as excellent, very good, good, fair, or poor.

${ }^{i}$ Responded 15 days or more when asked the number days in the past month that his/her physical health, which includes physical illness and injury, had not been good.

${ }^{j}$ Responded 15 days or more when asked the number of days in the past month that his/her mental health, which includes stress, depression, and problems with emotions, had not been good.

${ }^{k}$ Current $=$ smoked at least 100 cigarettes in his/her lifetime and currently smokes either some days or every day; former $=$ smoked at least 100 cigarettes in his $/$ her lifetime but no longer smokes.

'Responded 1 or more hours when asked the number of hours exposed to other people's tobacco smoke when at work in the past 7 days.

The opinions expressed by authors contributing to this journal do not necessarily reflect the opinions of the U.S. Department of Health and Human Services, the Public Health Service, the Centers for Disease Control and Prevention, or the authors' affiliated institutions. 
Table 2. Massachusetts Workers ${ }^{\mathrm{a}} \mathrm{n}=35,906$ Aged 40 to 70 , by Occupation $^{\mathrm{b}}$, COPD Status $^{\mathrm{c}}$, and Age Group, Massachusetts BRFSS, 2011-2017

\begin{tabular}{|c|c|c|c|c|}
\hline \multirow[b]{2}{*}{ Census Occupation (Code) } & \multicolumn{3}{|c|}{ Age, $y^{d}$} & \multirow[b]{2}{*}{ Overall $^{\mathrm{e}}$} \\
\hline & $40-50$ & $51-60$ & $61-70$ & \\
\hline \multicolumn{5}{|l|}{ With COPD } \\
\hline All groups, no. ${ }^{f}$ & 290 & 591 & 459 & 1,340 \\
\hline $\begin{array}{l}\text { Management, Business and Financial Operations (COC } \\
\text { 0010-0950) }\end{array}$ & $10.8(5.9-15.7)$ & $13.9(9.4-18.4)$ & $12.1(6.9-17.3)$ & $12.5(9.7-15.4)$ \\
\hline Professional and Related (1000-3540) & $18.1(12.3-23.9)$ & $23.3(18.1-28.5)$ & $24.0(18.6-29.4)$ & $22.0(18.8-25.2)$ \\
\hline Service (3600-4650) & $26.9(19.8-34.0)$ & $16.1(10.7-21.6)$ & $16.4(10.9-21.9)$ & $19.3(15.8-22.8)$ \\
\hline Sales and Related (4700-4960) & $8.4(3.8-12.9)$ & $7.0(4.0-10.1)$ & $13.7(8.5-19.0)$ & $9.2(6.8-11.6)$ \\
\hline Office and Administrative Support (5000-5930) & $14.8(8.5-21.0)$ & $18.7(13.8-23.6)$ & $16.2(10.8-21.5)$ & $16.9(13.8-20.1)$ \\
\hline Transportation and Material Moving (9000-9750) & $6.4(2.2-10.6)$ & $4.4(2.4-6.5)$ & $6.9(3.4-10.4)$ & $5.7(3.9-7.4)$ \\
\hline Other & $14.6(8.0-21.2)$ & $16.5(10.9-22.0)$ & $10.6(6.5-14.7)$ & $14.4(11.0-17.7)$ \\
\hline \multicolumn{5}{|l|}{ Without COPD } \\
\hline All groups, no. ${ }^{f}$ & 10,865 & 12,228 & 6,722 & 29,815 \\
\hline $\begin{array}{l}\text { Management, Business and Financial Operations (COC } \\
\text { 0010-0950) }\end{array}$ & $17.8(16.8-18.8)$ & $16.4(15.5-17.4)$ & $16.0(14.8-17.2)$ & $17.0(16.4-17.6)$ \\
\hline Professional and Related (1000-3540) & $34.6(33.4-35.9)$ & $35.5(34.3-36.7)$ & $37.4(35.8-39.0)$ & $35.4(34.7-36.2)$ \\
\hline Service (3600-4650) & $12.7(11.8-13.7)$ & $11.4(10.6-12.3)$ & $10.9(9.8-12.1)$ & $11.9(11.4-12.5)$ \\
\hline Sales and Related (4700-4960) & $7.7(7.0-8.4)$ & $7.8(7.1-8.4)$ & $9.3(8.3-10.4)$ & $8.0(7.6-8.4)$ \\
\hline Office and Administrative Support (5000-5930) & $9.6(8.8-10.4)$ & $11.1(10.3-11.9)$ & $11.3(10.2-12.4)$ & $10.5(10.0-11.0)$ \\
\hline Transportation and Material Moving (9000-9750) & $3.8(3.2-4.4)$ & $4.2(3.6-4.8)$ & $3.6(2.8-4.3)$ & $3.9(3.5-4.3)$ \\
\hline Other & $13.7(12.7-14.7)$ & $13.5(12.5-14.5)$ & $11.4(10.1-12.8)$ & $13.3(12.6-13.9)$ \\
\hline
\end{tabular}

Abbreviations: BRFSS, Behavioral Risk Factor Surveillance System; COPD, chronic obstructive pulmonary disease.

${ }^{a}$ Employed for wages, self-employed, or out of work for less than 1 year.

${ }^{\mathrm{b}}$ Response to the following question categorized using 2002 Census Occupation Codes: "What kind of work did you do? For example, registered nurse, janitor, cashier, auto mechanic."

c "Yes" (with COPD) or "no" (without COPD) response to the question: "Has a doctor, nurse, or other health professional ever told you that you had chronic obstructive pulmonary disease or COPD, emphysema, or chronic bronchitis?"

${ }^{d}$ Values are percentage $(95 \% \mathrm{Cl})$ unless otherwise indicated. Percentages are weighted and may not total $100 \%$ because of rounding.

${ }^{e} P<.001$ from the $x^{2}$ test of independence comparing the occupation distribution overall between those with and without COPD.

${ }^{f}$ Unweighted number of respondents who answered the corresponding question(s). Those with missing or noncodable responses to the occupation question $(\mathrm{n}=$ 4,751) were excluded from analyses of occupation group. 